\title{
Symptomatic Acute Pancreatitis Induced by Nilotinib: A Report of Two Cases
}

\author{
Toshiki Yamada ${ }^{1}$, Yasuhito Nannya ${ }^{2,3}$, Masahito Shimizu ${ }^{2}$, \\ Mitsuru Seishima ${ }^{3,4}$ and Hisashi Tsurumi ${ }^{2}$
}

\begin{abstract}
Nilotinib is a selective tyrosine kinase inhibitor for the treatment of Philadelphia chromosome-positive leukemias. An elevation of the pancreatic enzyme level is one of the major adverse events associated with nilotinib, but whether or not nilotinib induces symptomatic pancreatitis remains to be elucidated. The cases of two chronic myeloid leukemia patients treated with nilotinib who developed symptomatic acute pancreatitis on the third and fifth day of nilotinib administration are herein presented. Since both patients had no other etiologies for pancreatitis, nilotinib was considered to be the causal agent. The withdrawal of nilotinib resulted in a prompt recovery. These cases underline the importance of recognizing pancreatitis as a possible adverse event associated with nilotinib.
\end{abstract}

Key words: acute pancreatitis, nilotinib, chronic myeloid leukemia

(Intern Med 55: 3495-3497, 2016)

(DOI: 10.2169/internalmedicine.55.7104)

\section{Introduction}

Nilotinib is an aminophenylpyrimidine-derived tyrosine kinase inhibitor (TKI) with a selective effect against Abl tyrosine kinase, and it now constitutes one of the key drugs of molecular targeting therapy for Bcr-Abl-positive leukemia. One significant adverse effect of nilotinib is an elevation of the pancreatic enzyme levels, with reported frequencies spanning from $1.7 \%$ to $17.6 \%$ (1-7). However, it remains unclear as to whether or not this phenomenon has any practical implications, i.e., this ultimately leads to symptomatic pancreatitis. At the present time, an almost total lack of relevant cases has made it difficult to resolve this issue, thus catching physicians off-guard. Two cases of nilotinibinduced acute pancreatitis are herein presented that provide some reasons to reconsider this issue.

\section{Case Reports}

Case 1: A 74-year-old man was referred to our institution after it was noticed that he had marked leukocytosis [white blood cell (WBC): $38.1 \times 10^{9} / \mathrm{L}$ ] in a screening examination. He had no history of pancreatitis. He was asymptomatic and had no hepatosplenomegaly. He had suffered from benign prostate hypertrophy and pulmonary emphysema. A complete blood count showed an increased WBC of $32.9 \times 10^{9} / \mathrm{L}$ with relative myeloid hypertrophy, a left shift, and no blasts (myelocytes: 2\%, metamyelocytes: 5\%, neutrophils: 77\%, eosinophils: $2 \%$, basophils: $1 \%$, lymphocytes: $8 \%$, monocytes: 5\%). The hemoglobin ( $\mathrm{Hb} ; 126 \mathrm{~g} / \mathrm{L})$ and platelet $\left(21.7 \times 10^{10} / \mathrm{L}\right)$ levels were normal. He had a normal organ function, including normal pancreatic amylase (34 IU/L, normal range: 14-41 IU/L) and lipase (33 U/L, normal range: 17-57 U/L) levels. A bone marrow examination showed marked hypercellularity (nucleated cell counts: 83.6 $\left.\times 10^{4} / \mu \mathrm{L}\right)$ with increased megakaryocytes $(310 / \mu \mathrm{L})$. No increase in the number of blasts or dysplasia was observed. Karyotyping by G-banding technique demonstrated $46, X Y, t(9 ; 22)(q 34 ; q 11.2)$ in 20 of 20 cells. A diagnosis of chronic myeloid leukemia (CML) in the chronic phase (CP) was made, and nilotinib $600 \mathrm{mg} /$ day was started. On the

\footnotetext{
${ }^{1}$ Department of Hematology, Gifu Prefectural Medical Center, Japan, ${ }^{2}$ First Department of Internal Medicine, Gifu University, Japan, ${ }^{3}$ Department of Transfusion Medicine, Gifu University, Japan and ${ }^{4}$ Department of Informative Clinical Medicine, Gifu University Graduate School of Medicine, Japan

Received for publication January 12, 2016; Accepted for publication March 22, 2016

Correspondence to Dr. Hisashi Tsurumi, htsuru@gifu-u.ac.jp
} 


\section{A) Case 1}
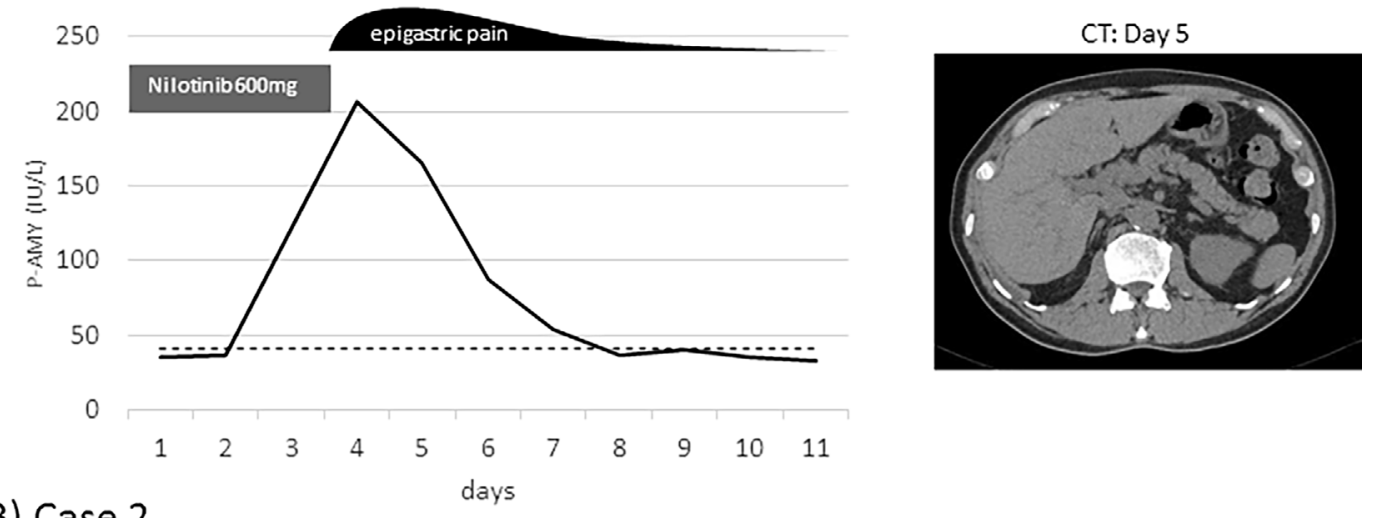

\section{B) Case 2}
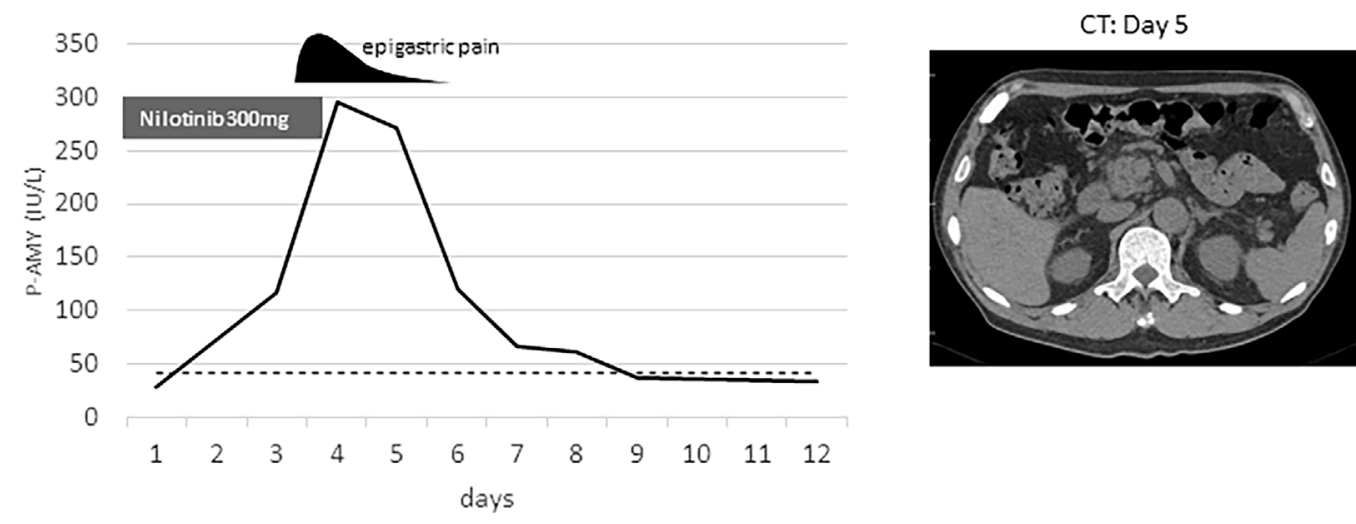

Figure. Graphical presentation of the present cases. Clinical courses of the two cases, A) case 1 and B) case 2 , are presented. The time from the start of nilotinib is shown by the vertical line. The dotted line indicates the upper normal limit of pancreatic amylase (P-AMY).

third day of nilotinib, the patient developed epigastric pain (grade 2 according to CTCAE ver. 4) and fever $\left(37.4^{\circ} \mathrm{C}\right.$ ). Laboratory examinations showed marked increases in the pancreatic amylase (206 IU/L, grade 4) and lipase (326 U/L, grade 4) levels. Computed tomography (CT) revealed swelling of the pancreatic tail, which was compatible with acute pancreatitis. Because he had no other causes of pancreatitis including hypertriglyceridemia, biliary tract obstruction, alcohol intake or diabetes mellitus, nilotinib was considered responsible for the pancreatitis and thus was immediately stopped. Thereafter, his condition improved promptly, with a resolution of the epigastric pain and normalization of pancreatic enzymes. The patient was switched to dasatinib and has since remained in good condition.

Case 2: A 73-year-old man presented to our hospital to undergo an investigation of leukocytosis $\left(29.7 \times 10^{9} / \mathrm{L}\right)$ with a high platelet level $\left(114.9 \times 10^{10} / \mathrm{L}\right)$ that were discovered during routine check-ups for a past myocardial infarction. A bone marrow examination revealed hypercellular marrow (nucleated cell counts: $42.8 \times 10^{4} / \mu \mathrm{L}$ ) with increased megakaryocytes $(868 / \mu \mathrm{L})$ and a myeloid-prone maturation. Twenty cells were examined, and all had Philadelphia chromosome by $\mathrm{G}$ karyotyping. CML-CP was diagnosed, and nilotinib $300 \mathrm{mg} /$ day was started. On the fifth day, the patient developed epigastric pain (grade 2$)$ and fever $\left(37.8^{\circ} \mathrm{C}\right.$ ). Laboratory data showed elevated pancreatic amylase (295/ $\mu \mathrm{L}$, grade 4) and lipase (487 U/L, grade 4) levels. Abdominal CT showed swelling of the pancreas head but no sign of bile duct obstruction. This patient was considered to have nilotinib-induced acute pancreatitis, because he had no history of pancreatitis, excessive alcohol intake, hyperlipidemia or biliary tract disease. Although he had been considered to have diabetes, sitagliptin provided good control (HbA1c 6.3\%). Nilotinib was stopped and the epigastric pain immediately subsided followed by the normalization of the pancreatic enzyme levels. His TKI was switched to dasatinib, and there has been no recurrence of pancreatitis. Both of these cases are presented in Figure.

\section{Discussion}

An elevation of pancreatic enzymes has been recognized as a major adverse event of nilotinib (1,3-7), but a clear description of the cases with symptomatic pancreatitis has been lacking. A total of 32 cases of pancreatitis have been reported to the Japanese Adverse Drug Event Report database of PMDA since nilotinib was introduced 7 years ago, but lack of any detailed data of these cases made the true association unclear. The incidence of pancreatitis in nilotinib-treated patients is estimated to be $0.28 \%$ judging from post-marketing surveillance data ( 2 cases of pancreatitis and 7 cases of acute pancreatitis were reported out of a 
total of 3,234 cases).

Both of the present cases featured a short latency from drug administration to the onset of acute pancreatitis, and this is consistent with Badalov's criteria for drug-induced acute pancreatitis which classified suspicious drugs according to the level of evidence, and the consistency of latency among reported cases is a key factor to support the etiological influence of this drug (8).

The mechanism of TKI-induced pancreatitis is not known, but it can be deduced by the presumed mechanism of elevation of the pancreatic enzyme levels by nilotinib, which includes pancreatic cell damage through inhibition of nonreceptor type tyrosine kinase $\mathrm{c}-\mathrm{Abl}$, and interference with pathways that regulate the exocrine secretion of pancreatic enzymes (9). A hypertriglyceridemia-mediated mechanism should also be considered, because hypertriglyceridemia is often seen as an adverse effect of nilotinib, and it is a wellknown risk factor for pancreatitis, accounting for up to $7 \%$ of all pancreatitis cases (10). However, the threshold for triglycerides to induce acute pancreatitis is considered to be relatively high, generally over $1,500 \mathrm{mg} / \mathrm{dL}$ (11), and neither of the present patients showed this level of elevation. Therefore, this mechanism seems remote in the present cases.

Abdominal pain, usually constant and located in the epigastrium, is one of the most typical symptoms of acute pancreatitis (9). The observation of this symptom in our patients drove us to proceed to detailed examinations, leading to the diagnosis of acute pancreatitis. It is noteworthy that the drug information sheet for nilotinib states that epigastric pain is commonly seen, with a reported incidence of $9.3 \%$ in Japan (12). This high rate of epigastric pain might include various etiologies. For example, gastric mucosal damage due to an increased level of serum histamine is a common symptom of chronic myeloid leukemia especially in the early treatment phase with massive residual disease, and thus presents as epigastric pain. We are concerned that acute pancreatitis is relegated to the bottom of the list when making a differential diagnosis because of the incorrect preconception that nilotinib does not cause pancreatitis. Considering the critical significance of the initial response in cases of acute pancreatitis, we cannot put enough emphasis on the need to suspect this etiology when encountering a case demonstrating epigastric pain. In the present cases, it was possible to successfully diagnose and deal with drug-induced pancreatitis, although we cannot completely rule out hyperhistaminemia as the cause of epigastric pain because the histamine levels were not measured.

In conclusion, nilotinib can cause not only a simple eleva- tion of the pancreatic enzyme levels, but also clinically significant pancreatitis. Further investigation is therefore required to determine the precise incidence, background characteristics, and risk factors underlying the symptomatic pancreatitis induced by nilotinib.

The authors state that they have no Conflict of Interest (COI).

\section{References}

1. Hazarika M, Jiang X, Liu Q, et al. Tasigna for chronic and accelerated phase Philadelphia chromosome-positive chronic myelogenous leukemia resistant to or intolerant of imatinib. Clin Cancer Res 14: 5325-5331, 2008.

2. Kantarjian H, Giles F, Wunderle L, et al. Nilotinib in imatinibresistant CML and Philadelphia chromosome-positive ALL. N Engl J Med 354: 2542-2551, 2006.

3. le Coutre P, Ottmann OG, Giles F, et al. Nilotinib (formerly AMN 107), a highly selective BCR-ABL tyrosine kinase inhibitor, is active in patients with imatinib-resistant or -intolerant acceleratedphase chronic myelogenous leukemia. Blood 111: 1834-1839, 2008.

4. Rosti G, Palandri F, Castagnetti F, et al. Nilotinib for the frontline treatment of $\mathrm{Ph}^{+}$chronic myeloid leukemia. Blood 114: 49334938, 2009.

5. Tojo A, Usuki K, Urabe A, et al. A Phase I/II study of nilotinib in Japanese patients with imatinib-resistant or -intolerant $\mathrm{Ph}^{+} \mathrm{CML}$ or relapsed/refractory $\mathrm{Ph}^{+}$ALL. Int J Hematol 89: 679-688, 2009.

6. Zhou L, Meng F, Yin O, et al. Nilotinib for imatinib-resistant or -intolerant chronic myeloid leukemia in chronic phase, accelerated phase, or blast crisis: a single- and multiple-dose, open-label pharmacokinetic study in Chinese patients. Clin Ther 31: 1568-1575, 2009.

7. Saglio G, Kim DW, Issaragrisil S, et al. Nilotinib versus imatinib for newly diagnosed chronic myeloid leukemia. N Engl J Med 362: 2251-2259, 2010.

8. Badalov N, Baradarian R, Iswara K, Li J, Steinberg W, Tenner S. Drug-induced acute pancreatitis: an evidence-based review. Clin Gastroenterol Hepatol 5: 648-661; quiz 644, 2007.

9. Jones MR, Hall OM, Kaye AM, Kaye AD. Drug-induced acute pancreatitis: a review. Ochsner J 15: 45-51, 2015.

10. Gan SI, Edwards AL, Symonds CJ, Beck PL. Hypertriglyceridemia-induced pancreatitis: a case-based review. World J Gastroenterol 12: 7197-7202, 2006.

11. McLaughlin T, Abbasi F, Lamendola C, Yeni-Komshian H, Reaven G. Carbohydrate-induced hypertriglyceridemia: an insight into the link between plasma insulin and triglyceride concentrations. J Clin Endocrinol Metab 85: 3085-3088, 2000.

12. PMDA. nilotinib drug information sheet. https://www.pmda.go.jp/

The Internal Medicine is an Open Access article distributed under the Creative Commons Attribution-NonCommercial-NoDerivatives 4.0 International License. To view the details of this license, please visit (https://creativecommons.org/licenses/ by-nc-nd/4.0/).

(C) 2016 The Japanese Society of Internal Medicine http://www.naika.or.jp/imonline/index.html 